\title{
X-ray micro-tomography as a diagnostic tool for the electrode degradation in vanadium redox flow batteries
}

\author{
Panagiotis Trogadas a, Oluwadamilola O. Taiwo ${ }^{\text {a }}$, Bernhard Tjaden ${ }^{a}$, Tobias P. Neville a, Sukhwan Yun ${ }^{\text {b }}$, \\ Javier Parrondo ${ }^{\mathrm{b}}$, Vijay Ramani ${ }^{\mathrm{b}}$, Marc-Olivier Coppens ${ }^{\mathrm{a}}$, Dan J.L. Brett ${ }^{\mathrm{a}}$, Paul R. Shearing ${ }^{\mathrm{a}, *}$

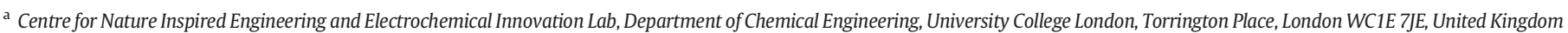 \\ b Center for Electrochemical Science and Engineering, Department of Chemical and Biological Engineering, Illinois Institute of Technology, Chicago, IL 60616, USA
}

\section{A R T I C L E I N F O}

Article history:

Received 28 August 2014

Received in revised form 9 September 2014

Accepted 9 September 2014

Available online 16 September 2014

\section{Keywords:}

X-ray micro-tomography

Vanadium redox flow battery

Electrode degradation

\begin{abstract}
A B S T R A C T
Micro-tomography (CT) can be successfully employed to characterize ex situ the structural changes occurring in graphite felt electrodes during vanadium redox flow battery (VRFB) operation. Coupled high resolution X-ray and electron microscopy in conjunction with XPS are used to elucidate the microstructural and chemical changes to the high voltage RFB carbon electrode. The results reveal the onset of corrosion of the carbon felt structure relatively early in the VRFB life-cycle, extended operation is expected to result in extensive microstructural evolution effects.
\end{abstract}

(C) 2014 The Authors. Published by Elsevier B.V. This is an open access article under the CC BY license (http://creativecommons.org/licenses/by/3.0/).

\section{Introduction}

The vanadium redox flow battery (VRFB) is an electrochemical device suitable for large-scale energy storage due to its fast response time, long cycle life, and high energy efficiency [1,2]. In VRFBs, the electrodes provide the sites to facilitate the redox reactions between $\mathrm{V}^{3+} / \mathrm{V}^{2+}$ and $\mathrm{V}^{4+} / \mathrm{V}^{5+}$ ions $[2,3]$.

Graphite felt is the most common electrode material employed in VRFBs due to its low cost, high stability and conductivity, and reasonable surface area $[4,5]$. To improve the activity of the felt, several surface treatments have been employed to alter the felt surface chemistry and, consequently, to improve the reaction kinetics at the electrodes. These include thermal activation [6], chemical etching/doping [1,7], nitrogen doping [8] and functionalization of the surface with hydroxyl groups [9]. Recent publications demonstrate that substantial performance gains can be achieved with improved design of these felt materials [10-13].

Tomograms of fresh graphite felt have already been obtained and used to extract detailed structural characteristics of electrodes (surface area, porosity, fiber diameter and volume) $[14,15]$. Based on the acquired structural information, 3D pore scale models have been built to investigate the effect of electrolyte flow rate, vanadium ion concentration and electrode morphology on VRFB performance. It has been found that overall cell voltage can be enhanced by increasing flow rate and by employing denser electrode structure $[14,15]$.

\footnotetext{
* Corresponding author. Tel.: + 442076793783.

E-mail address: p.shearing@ucl.ac.uk (P.R. Shearing).
}

However, even though this model-based design approach has helped optimize the fresh felt material, pore scale models for VRFBs would be much more accurate and realistic if the structural information of used (voltage-cycled) felts were incorporated in the model to capture the changes in felt structure and properties during operation.

Using a combination of micro-tomography (CT) measurements of voltage-cycled graphite felts (over ca. 30 charge/discharge cycles), scanning electron microscopy (SEM), and X-ray photoelectron spectroscopy (XPS) measurements of the same felt electrode, the first description of microstructural evolution processes occurring in VRFB felts during operation is provided in this paper.

\section{Experimental}

Graphite felts (Sigracell@; GFA6) were harvested from the positive electrode $\left(\mathrm{V}^{4+} / \mathrm{V}^{5+}\right)$ of a VRFB in a 'fresh' and 'used' state - 'fresh' felts were thermally activated and had undergone compression identical to those used in working VRFBs. 'Fresh' felts were in contact with the electrolyte solution, but had not been electrochemically cycled, whereas the 'used' felts underwent 33 charge/discharge cycles (Fig. 3(D)). Vanadium (IV) oxide sulfate (hydrate, 97\%) was used as the starting electrolyte solution. In order to prepare $\mathrm{V}^{2+}$ and $\mathrm{V}^{5+}$ ions, anolyte and catholyte were filled with $1: 2$ ratio of $\mathrm{V}(\mathrm{IV})$ solution ( $1.5 \mathrm{M}$ in $3 \mathrm{M} \mathrm{H}_{2} \mathrm{SO}_{4}$ ) respectively and the required ions were obtained by charging of the VRB. The resulting solutions in anolyte and catholyte were $1.5 \mathrm{M} \mathrm{V}^{2+} / \mathrm{V}^{3+}$ and $1.5 \mathrm{M} \mathrm{VO}^{2+} / \mathrm{VO}_{2}^{+}$respectively, both in $3 \mathrm{M}$ $\mathrm{H}_{2} \mathrm{SO}_{4}$ solution. Charge-discharge tests were conducted at a constant current density of $100 \mathrm{~mA} \mathrm{~cm}{ }^{-2}$ at $30{ }^{\circ} \mathrm{C}$. The cut-off voltages for the 
charge (upper limit) and discharge (lower limit) cycles were 1.65 and $0.65 \mathrm{~V}$, respectively. The maximum cut-off voltage used during charging $(1.65 \mathrm{~V})$ was selected based on the maximum potential the battery could hold without excessive hydrogen evolution. The lower cut-off cell voltage during discharge $(0.65 \mathrm{~V})$ was selected to allow complete discharge of the battery.

Samples of 'fresh' and 'used' graphite felts were characterized in 3D using the micro-CT facility at the TOMCAT beamline at the Swiss Light Source. Using a parallel beam setup at $10.5 \mathrm{keV}$ in absorption mode, 1500 projections were acquired for each tomographic scan during a $180^{\circ}$ rotation with a radiation exposure time of $200 \mathrm{~ms}$ for each projection image, providing an effective pixel size of $0.65 \mu \mathrm{m}$. Tomographic reconstruction of the acquired projection images was performed using the Gridrec algorithm [16] after application of flat and dark field corrections. Image analysis of the raw data was performed using the Avizo Fire software package (FEI): for each acquired tomographic volume, a cubic region-of-interest $\left(0.48 \mathrm{~mm}^{3}\right)$ was extracted for subsequent analysis, a smoothing filter was then applied to the grayscale image sequences for image de-noising; followed by a watershed segmentation to separate the solid phase (graphite fibers) from the pore phase, this is a well-established work-flow that has previously been applied to graphite materials [17].

\section{Results and discussion}

Cross-sections of the micro-tomograms of 'fresh' and voltage-cycled graphite felts are shown in Figs. 1(a) and 2(a). 'Fresh' graphite felt fibers have uniform density, whereas an alteration of the structure of the used voltage-cycled graphite felts is observed, this micro structural evolution is manifested as the appearance of agglomerated fiber bundles, and non-uniform density across individual fibers, consistent with electrochemical oxidation of the carbon structure.

The observed structural changes were verified by the 3D reconstructed images of graphite felt samples. 'Fresh' graphite felt (Fig. 1(B)) consists of individual fibers (fiber size $\sim 13 \mu \mathrm{m}$ ) forming 'bundles' throughout its structure, whereas the voltage-cycled felt (Fig. 2(B)) structure is dominated by agglomerated fibers.

Key geometric characteristics of the graphite felt samples (porosity, volume specific surface area and characteristic tortuosity) can be extracted from the 3D reconstructed images. Tortuosity values were calculated using an established methodology in StarCCM ${ }^{+}$software (see [18]). A small decrease in the calculated porosity and increase in tortuosity values [18] is observed in the case of voltage-cycled graphite felt as a consequence of the charge/discharge cycling for a short period of time $(\sim 65 \mathrm{~h})$. A small increase in the pore phase characteristic tortuosity of voltage-cycled electrode is observed due to the densification of the structure as a result of graphite felt oxidation. However, there is a significant reduction $(\sim 37 \%)$ in the volume specific surface area of the voltage-cycled graphite felt sample after $60 \mathrm{~h}$ of continuous VRFB testing, indicating its structural alteration due to carbon oxidation and fiber agglomeration (Table 1). BET was employed to experimentally verify the observed changes in surface area by CT. The BET surface area of the 'fresh' sample was $23 \mathrm{~m}^{2} \mathrm{~g}^{-1}$ and it was reduced to $14 \mathrm{~m}^{2} \mathrm{~g}^{-1}$ for the voltage cycled sample, indicating a similar reduction in the surface area of the voltage-cycled graphite felt sample. This significant change in the microstructure of the felt will influence the microscopic transport and reaction phenomena occurring in the electrode, and thereby affect device-level performance.
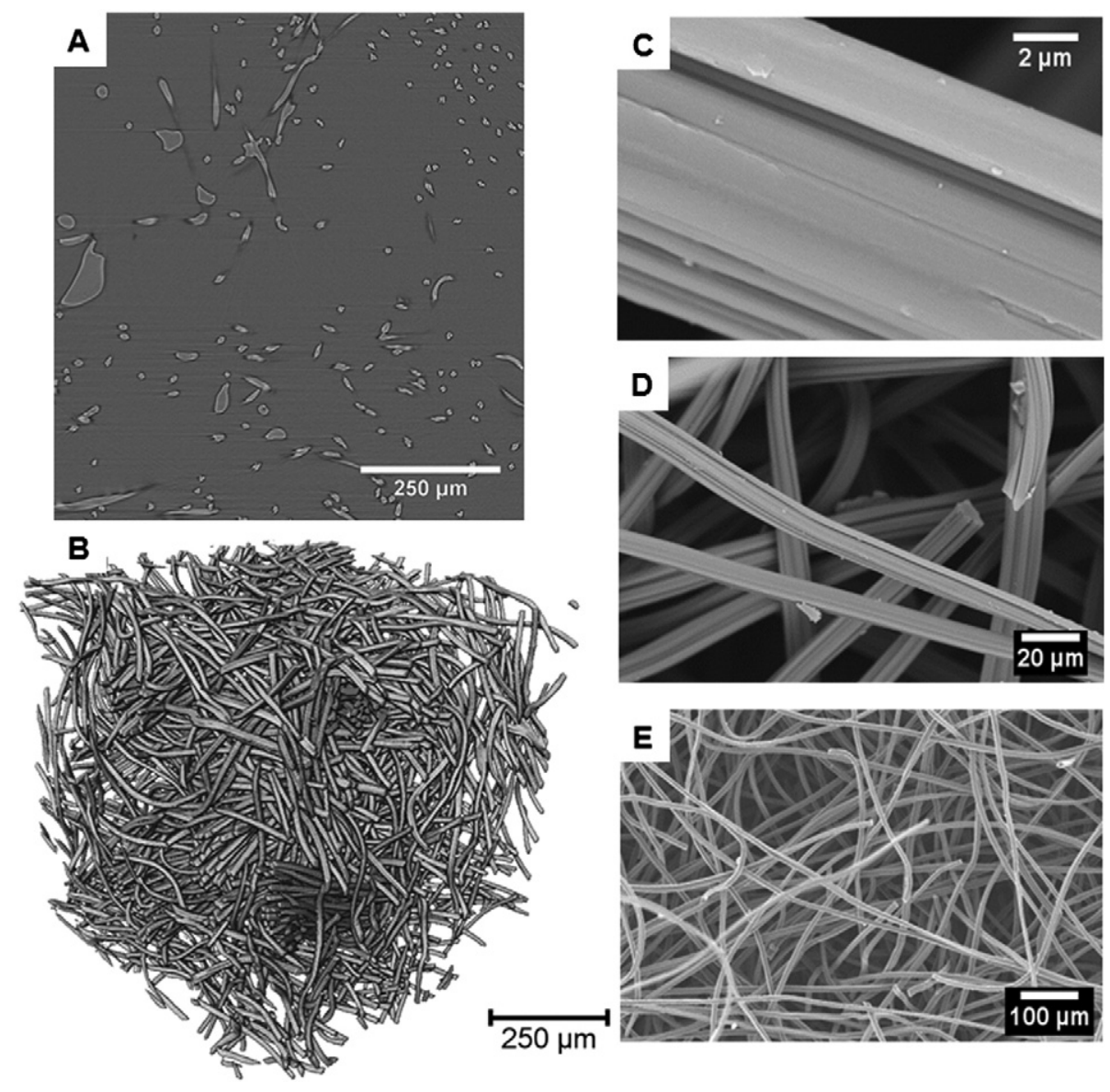

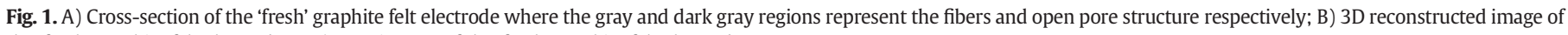
the 'fresh' graphite felt electrode; c-e) SEM images of the 'fresh' graphite felt electrode. 

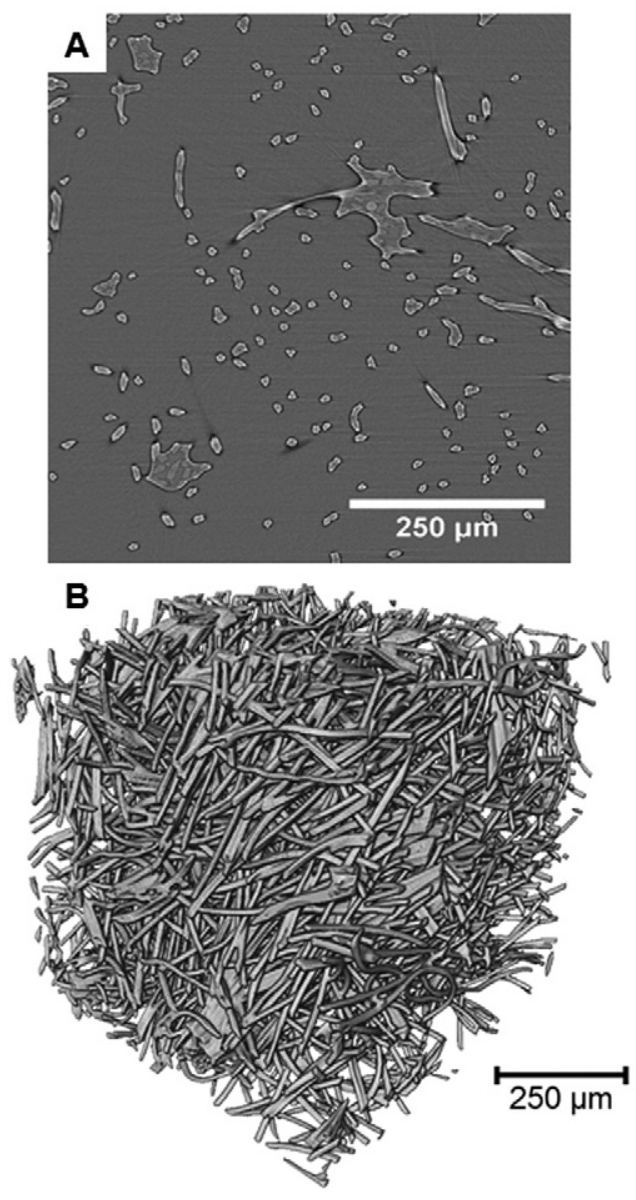
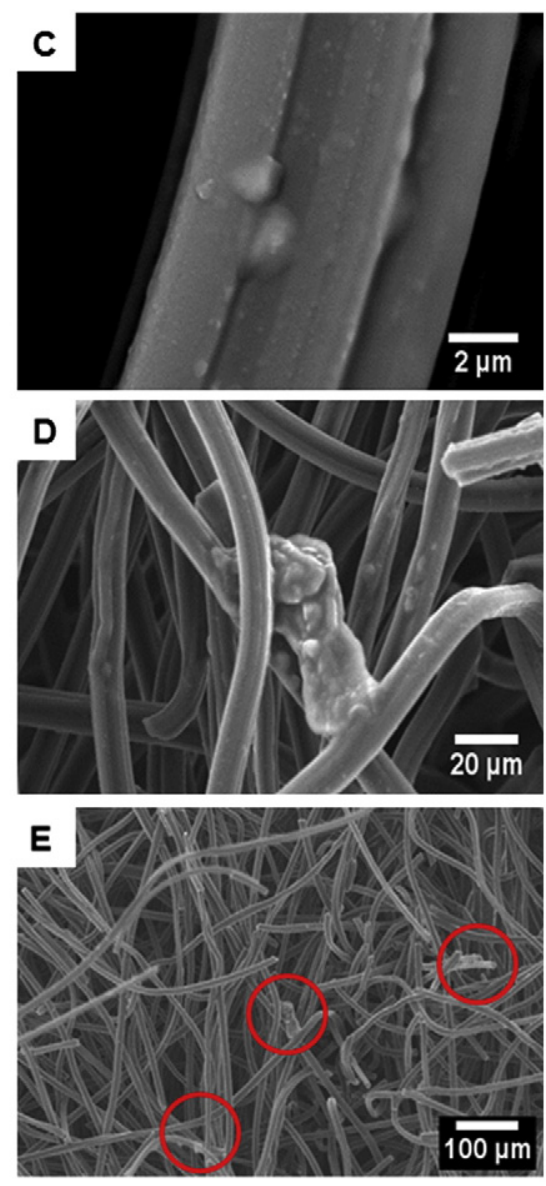

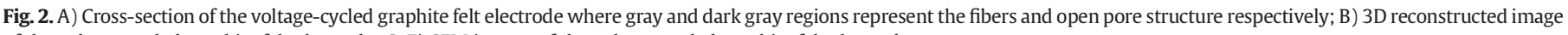
of the voltage-cycled graphite felt electrode; C-E) SEM images of the voltage-cycled graphite felt electrode.

These structural changes observed using micro-CT have been verified using SEM, while XPS was used to investigate the changes on the surface of voltage-cycled electrodes.

SEM images of 'fresh' graphite felt (Fig. 1(C)-(E)) show that the individual fibers $(\sim 10 \mu \mathrm{m}$ diameter $)$ comprise bundles of several smaller fibers ( 3-4 $\mu$ m diameter each). The appearance of a few small cavities on the surface (Fig. 1(C)) was induced by thermal oxidation of the 'fresh' sample at $400{ }^{\circ} \mathrm{C}$ for $30 \mathrm{~h}$ to increase the surface area of the graphite felt $[19,20]$ prior to VRFB charge/discharge cycling. Moreover, the bundle structure of the graphite felt results in edge planes and high defect concentration [21], and hence it is expected that the graphite felt fibers will react with oxygen and rapidly form highly oxidized carbon-oxygen groups $[21,22]$. SEM images of voltage-cycled graphite felts confirm this expectation by revealing layered oxidized graphite fibers beginning to agglomerate.

XPS studies have also been conducted to determine the surface chemical state of graphite felt before and after voltage cycling. The oxygen-to-carbon molar ratio increases from 0.09 to 0.39 in the case of the voltage cycled graphite felt; this pronounced $300 \%$ increase in

Table 1

Geometrical properties of 3D reconstructed graphite felt electrodes.

\begin{tabular}{lll}
\hline & 'Fresh' felt & Voltage-cycled felt \\
\hline Porosity & 0.941 & 0.924 \\
Volume-specific surface area $\left(\mu \mathrm{m}^{-1}\right)$ & 0.495 & 0.328 \\
Characteristic tortuosity [18] & 1.014 & 1.026 \\
\hline
\end{tabular}

surface oxygen content confirms that electrochemical oxidation of carbon occurs on the surface.

The C $1 \mathrm{~s}$ spectra for both 'fresh' and voltage-cycled graphite felts are asymmetric, with a tailing at the high energy binding side, which is typical for highly graphitized carbon fibers $[21,23]$. The C $1 \mathrm{~s}$ spectra of voltage-cycled graphite felt confirms the formation of $\mathrm{COOH}$ $(\sim 288.6 \mathrm{eV})$, a carbon oxidation intermediate [24,25].

Additionally, the $01 \mathrm{~s}$ spectra of voltage-cycled graphite felts demonstrate that there is a considerable increase in the carboxylic surface groups ( $\mathrm{C}=\mathrm{O}$ and/or $\mathrm{C}-\mathrm{O}-\mathrm{C}$ ), accompanied by a decrease in $\mathrm{C}-\mathrm{OH}$ surface concentration; $\sim 76 \% \mathrm{C}=\mathrm{O}$ and $24 \% \mathrm{C}-\mathrm{OH}$ present on voltage-cycled graphite felt compared to $~ 60 \% \mathrm{C}-\mathrm{OH}$ and $20 \%$ $\mathrm{C}=\mathrm{O}$ present on 'fresh' graphite felt. These results suggest that the graphite felt has a strong tendency to interact with oxygen and form highly oxidized $\mathrm{C}=\mathrm{O}$ species. Moreover, the observed $\mathrm{C}-\mathrm{OH}$ reduction has an effect on the overall electrochemical reaction activity of the electrode as $\mathrm{C}-\mathrm{OH}$ species enhance the absorption of vanadium ions on the surface of the electrode and catalyze the redox reaction between $\mathrm{V}^{4+}$ and $\mathrm{V}^{5+}$ ions [6]. The charge and discharge processes at the positive electrode involve oxygen transfer from the $\mathrm{C}-\mathrm{O}-\mathrm{H}$ bond to $\mathrm{VO}^{2+}$ forming a surface $\mathrm{VO}_{2}^{+}$that diffuses back to the solution (Eq. (1)) [6,26].

$\mathrm{C}-\mathrm{OH}+\mathrm{VO}^{2+} \leftrightarrow \mathrm{C}-\mathrm{O}-\mathrm{V}=\mathrm{O}^{+}+\mathrm{H}^{+}$

Thus, XPS results confirm that voltage-cycled graphite felt undergoes electrochemical oxidation during operation, resulting in the formation of carbon oxidation products $(\mathrm{COOH})$ on the electrode 

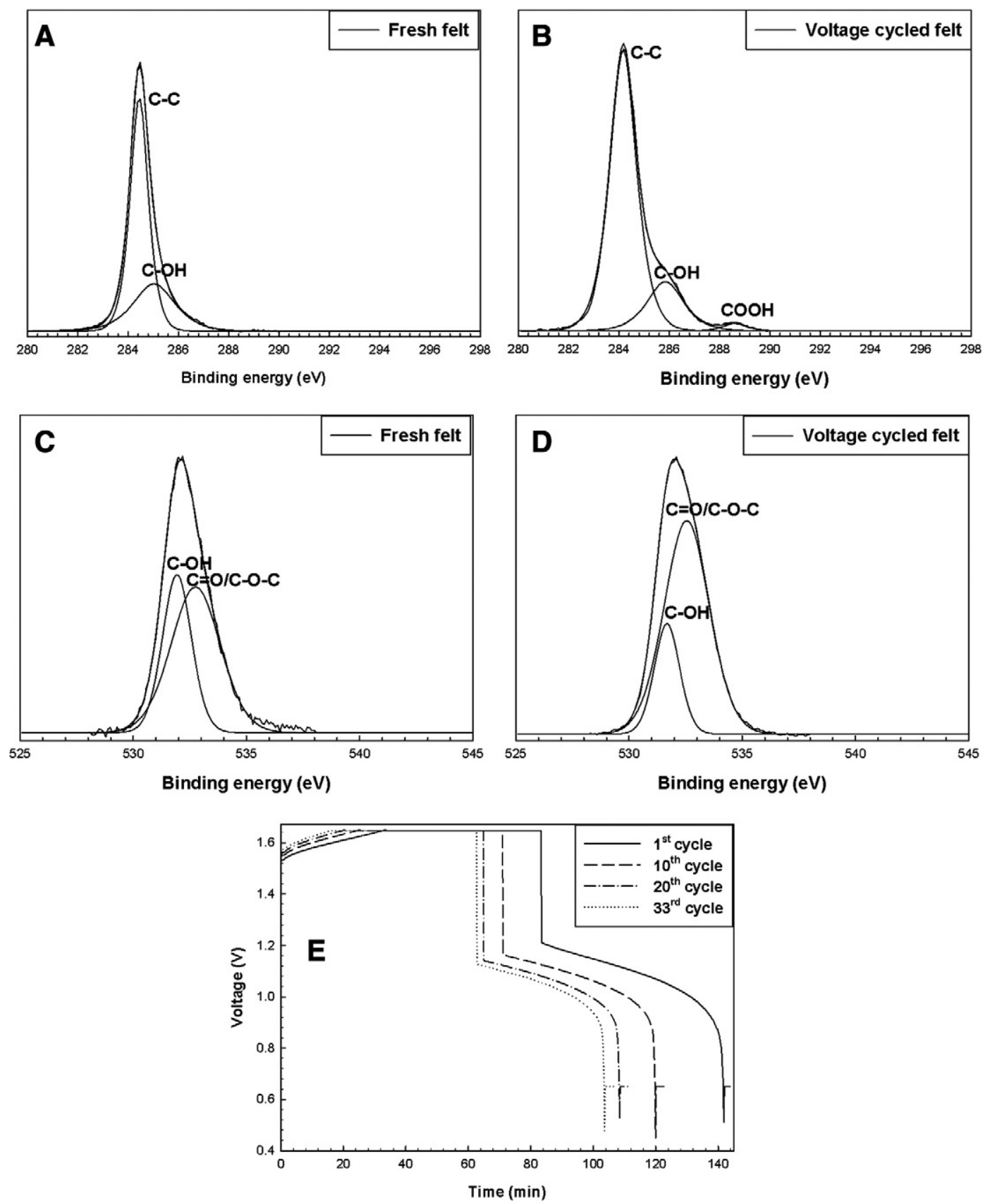

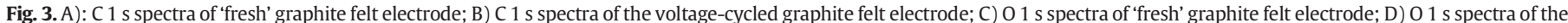
voltage-cycled graphite felt electrode; E) VRFB charge/discharge cycles (two laminated Nafion ${ }^{\circledR} 211$ membranes as separator, current density: $100 \mathrm{~mA} \mathrm{~cm}^{-2}$, $30{ }^{\circ} \mathrm{C}$ ).

surface and the reduction of surface $\mathrm{COH}$ species. The presence of $\mathrm{C}=\mathrm{O}$ and $\mathrm{COOH}$ catalyzes the formation of $\mathrm{CO}_{2}$ accelerating the oxidation rate of the electrode [25,27].

Fig. 3(E) shows the charge-discharge curves obtained on a VRFB assembled with two laminated Nafion ${ }^{\circledR} 211$ membranes (similar thickness to Nafion ${ }^{\circledR} 112$ ) as separator. The data were obtained within a voltage window of $0.65-1.65 \mathrm{~V}$ at $100 \mathrm{~mA} \mathrm{~cm}^{-2}$ current density: preliminary charging tests at higher cut-off voltages resulted in the formation of abundant hydrogen bubbles at the negative electrode at cell voltages above $1.7 \mathrm{~V}$. The 1 st cycle has a lower charge voltage plateau and higher discharge plateau than the subsequent cycles, indicating that the voltage efficiency of the VRFB is higher before electrochemical oxidation of the electrode occurs. Voltage efficiency is gradually reduced as the number of charge/discharge cycles increases. An overall 30\% capacity reduction is observed, while the retention time of the last discharge (33rd cycle) is also decreased due to electrolyte and solvent transfer from the positive to the negative half-cell [28-31].

\section{Conclusions}

Micro-CT is an exceptional diagnostic tool for monitoring the structural changes occurring in graphite felt electrodes during VRFB operation. Reconstructed 3D images of the VRFB electrodes reveal fiber agglomeration and carbon electrochemical oxidation during continuous battery operation. Key geometric characteristics of the graphite felt samples can also be extracted from these 3D images allowing the calculation of porosity, characteristic tortuosity and volume specific surface area (and the changes therein) for each sample. In this study, a significant decrease $(\sim 37 \%)$ in the volume specific surface area of 
voltage-cycled graphite felts is observed after only $65 \mathrm{~h}$ of continuous VRFB testing, indicating its structural alteration due to carbon oxidation/fiber agglomeration. SEM and XPS are employed to verify the structural and surface changes observed by micro-CT. SEM shows fibers with bundle structure starting to agglomerate after VRFB cycling and XPS confirms the electrochemical oxidation of graphite fibers, demonstrating the formation of an intermediate carbon oxidation product $(\mathrm{COOH})$ on the electrode surface.

\section{Conflict of interest}

The authors state that there is no conflict of interest.

\section{Acknowledgments}

Tomography experiments were performed on the TOMCAT Beamline at the Swiss Light Source, Paul Scherrer Institute, Villigen, Switzerland. We are grateful to R. Mokso, J. Fife and D. Harberthur at Swiss Light Source whose outstanding efforts have made these experiments possible. PRS acknowledges financial support from the Royal Academy of Engineering. We acknowledge the EPSRC for funding through EP/L014289/1 and EP/K038656/1. VR would like to acknowledge the Hyosung S. R. Cho Endowed Chair Professorship for funding this collaboration. MOC, DJLB, TPN and PT gratefully acknowledge the EPSRC for funding via a "Frontier Engineering" Award, EP/K038656/1.

\section{References}

[1] A. Weber, M. Mench, J. Meyers, P. Ross, J. Gostick, Q. Liu, Redox flow batteries: a review, J. Appl. Electrochem. 41 (2011) 1137-1164.

[2] A. Parasuraman, T.M. Lim, C. Menictas, M. Skyllas-Kazacos, Review of material research and development for vanadium redox flow battery applications, Electrochim. Acta 101 (2013) 27-40.

[3] B. Li, M. Gu, Z. Nie, Y. Shao, O. Luo, X. Wei, X. Li, J. Xiao, C. Wang V. Sprenkle, W. Wang, Bismuth nanoparticle decorating graphite felt as a high-performance electrode for an all-vanadium redox flow battery, Nano Lett. 13 (2013) 1330-1335.

[4] M.H. Chakrabarti, N.P. Brandon, S.A. Hajimolana, F. Tariq, V. Yufit, M.A. Hashim, M.A Hussain, C.T.J. Low, P.V. Aravind, Application of carbon materials in redox flow batteries, J. Power Sources 253 (2014) 150-166.

[5] P. Trogadas, T.F. Fuller, P. Strasser, Carbon as catalyst and support for electrochemical energy conversion, Carbon 75 (2014) 5-42.

[6] B. Sun, M. Skyllas-Kazacos, Modification of graphite electrode materials for vanadium redox flow battery application-I. Thermal treatment, Electrochim. Acta 37 (1992) 1253-1260.

[7] C. Ponce-de-León, G.W. Reade, I. Whyte, S.E. Male, F.C. Walsh, Characterization of the reaction environment in a filter-press redox flow reactor, Electrochim. Acta 52 (2007) 5815-5823.

[8] S. Wang, X. Zhao, T. Cochell, A. Manthiram, Nitrogen-doped carbon nanotube/graphite felts as advanced electrode materials for vanadium redox flow batteries, J. Phys. Chem Lett. 3 (2012) 2164-2167.

[9] C.U. Pittman Jr., G.-R. He, B. Wu, S.D. Gardner, Chemical modification of carbon fiber surfaces by nitric acid oxidation followed by reaction with tetraethylenepentamine, Carbon 35 (1997) 317-331.

[10] D. Aaron, C.-N. Sun, M. Bright, A.B. Papandrew, M.M. Mench, T.A. Zawodzinski, In situ kinetics studies in all-vanadium redox flow batteries, ECS Electrochem. Lett. 2 (2013) A29-A31.
[11] Q. Liu, A. Turhan, T.A. Zawodzinski, M.M. Mench, In situ potential distribution measurement in an all-vanadium flow battery, Chem. Commun. 49 (2013) 6292-6294

[12] Q.H. Liu, G.M. Grim, A.B. Papandrew, A. Turhan, T.A. Zawodzinski, M.M. Mench, High performance vanadium redox flow batteries with optimized electrode configuration and membrane selection, J. Electrochem. Soc. 159 (2012) A1246-A1252.

[13] C.-N. Sun, F.M. Delnick, D.S. Aaron, A.B. Papandrew, M.M. Mench, T.A. Zawodzinski, Probing electrode losses in all-vanadium redox flow batteries with impedance spectroscopy, ECS Electrochem. Lett. 2 (2013) A43-A45.

[14] G. Qiu, A.S. Joshi, C.R. Dennison, K.W. Knehr, E.C. Kumbur, Y. Sun, 3-D pore-scale resolved model for coupled species/charge/fluid transport in a vanadium redox flow battery, Electrochim. Acta 64 (2012) 46-64.

[15] G. Qiu, C.R. Dennison, K.W. Knehr, E.C. Kumbur, Y. Sun, Pore-scale analysis of effects of electrode morphology and electrolyte flow conditions on performance of vanadium redox flow batteries, J. Power Sources 219 (2012) 223-234.

[16] F. Marone, M. Stampanoni, Regridding reconstruction algorithm for real-time tomographic imaging, J. Synchrotron Radiat. 19 (2012) 1029-1037.

[17] D.S. Eastwood, R.S. Bradley, F. Tariq, S.J. Cooper, O.O. Taiwo, J. Gelb, A. Merkle, D.J.L. Brett, N.P. Brandon, P.J. Withers, P.D. Lee, P.R. Shearing, The application of phase contrast X-ray techniques for imaging Li-ion battery electrodes, Nucl. Inst. Methods Phys. Res. B 324 (2014) 118-123.

[18] S.J. Cooper, D.S. Eastwood, J. Gelb, G. Damblanc, DJ.L. Brett, R.S. Bradley, PJ. Withers, P.D. Lee, A.J. Marquis, N.P. Brandon, P.R. Shearing, Image based modelling of microstructural heterogeneity in LiFePO4 electrodes for Li-ion batteries, J. Power Sources 247 (2014) 1033-1039.

[19] L. Zhang, Z.-G. Shao, X. Wang, H. Yu, S. Liu, B. Yi, The characterization of graphite felt electrode with surface modification for $\mathrm{H} 2 / \mathrm{Br} 2$ fuel cell, J. Power Sources 242 (2013) 15-22.

[20] K.J. Kim, Y.-J. Kim, J.-H. Kim, M.-S. Park, The effects of surface modification on carbon felt electrodes for use in vanadium redox flow batteries, Mater. Chem. Phys. 131 (2011) 547-553.

[21] S. Zhong, C. Padeste, M. Kazacos, M. Skyllas-Kazacos, Comparison of the physical, chemical and electrochemical properties of rayon- and polyacrylonitrile-based graphite felt electrodes, J. Power Sources 45 (1993) 29-41.

[22] L.S. Singer, I.C. Lewis, Applications of ESR to carbonaceous materials, Appl. Spectrosc. 36 (1982) 52-57.

[23] A. Proctor, P.M.A. Sherwood, X-ray photoelectron spectroscopic studies of carbon fibre surfaces. I. Carbon fibre spectra and the effects of heat treatment, J. Electron Spectrosc. Relat. Phenom. 27 (1982) 39-56.

[24] X.-g. Li, K.-l. Huang, S.-q. Liu, N. Tan, L.-q. Chen, Characteristics of graphite felt electrode electrochemically oxidized for vanadium redox battery application, Trans. Nonferrous Metals Soc. China 17 (2007) 195-199.

[25] H. Liu, Q. Xu, C. Yan, Y. Qiao, Corrosion behavior of a positive graphite electrode in vanadium redox flow battery, Electrochim. Acta 56 (2011) 8783-8790.

[26] W. Zhang, J. Xi, Z. Li, H. Zhou, L. Liu, Z. Wu, X. Qiu, Electrochemical activation of graphite felt electrode for $\mathrm{VO} 2+/ \mathrm{VO} 2+$ redox couple application, Electrochim. Acta 89 (2013) 429-435.

[27] H. Liu, Q. Xu, C. Yan, On-line mass spectrometry study of electrochemical corrosion of the graphite electrode for vanadium redox flow battery, Electrochem. Commun. 28 (2013) 58-62.

[28] X. Li, H. Zhang, Z. Mai, H. Zhang, I. Vankelecom, Ion exchange membranes for vanadium redox flow battery (VRB) applications, Energy Environ. Sci. 4 (2011) 1147-1160.

[29] T. Mohammadi, M.S. Kazacos, Modification of anion-exchange membranes for vanadium redox flow battery applications, J. Power Sources 63 (1996) 179-186.

[30] S. Yun, J. Parrondo, V. Ramani, Derivatized cardo-polyetherketone anion exchange membranes for all-vanadium redox flow batteries, J. Mater. Chem. A 2 (2014) 6605-6615.

[31] M.-s.J. Jung, J. Parrondo, C.G. Arges, V. Ramani, Polysulfone-based anion exchange membranes demonstrate excellent chemical stability and performance for the all-vanadium redox flow battery, J. Mater. Chem. A 1 (2013) 10458-10464. 